\title{
Chronic Granulomatous Disease: A Rare Hereditary Immuno-deficiency Disorder in a Young Boy with Its Adverse Consequences
}

\author{
MM RASHID $^{\mathrm{a}}, \mathrm{ANIGAR}^{\mathrm{b}}$, MR HASSAN $^{\mathrm{C}}$
}

Summary:

Chronic granulomatous disease (CGD) is a primary immunodeficiency disease which results from absence of the NADPH oxidase in the professional phagocytic cells neutrophils, monocytes, macrophages and eosinophils. Deficiency of this oxidase renders the patient liable to infection by bacteria and fungi, and, as the name of the disease suggests, to chronic granulomatous inflammation. Here, a young boy presented with increasing breathlessness and productive cough had recurrent episode of pulmonary infection since his childhood. Repeated Chest X-ray and CT scan showed homogenous opacities at different places of lung in different occasions with bilateral reticulo-nodular opacities. Mulipleoraganisms were isolated from sputum at different times. A nitroblu-tetrazolium test (NBT) was done abroad which was positive and confirmed his diagnosis. Since then,

\section{Introduction:}

Chronic granulomatous disease (CGD) is a rare inherited primary immunodeficiency, first described in the 1950s, in which defective phagocyte killing renders patients susceptible to severe, recurrent life-threatening bacterial and fungal infections ${ }^{1,2}$. Inheritance is usually X-linked (XL), but can be autosomal recessive (AR). Defects in components of nicotinamide adenine dinucleotide phosphate-oxidase leave phagocytes unable to generate reactive oxygen radicles necessary to eliminate ingested

a. Dr. Mamunur Rashid, Registrar, National Institute of the Chest and Hospital, Dhaka, Bangladesh.

b. Dr. Asfia Nigar, Assistant Professor, Intensive Care Unit, National Institute of the Chest and Hospital, Dh aka, Bangladesh.

c. Prof. Md. Rashidul Hassan, Director cum Professor, National Institute of the Chest and Hospital, Dhaka, Bangladesh.

Address of Correspondence: Dr. Mamunur Rashid, Registrar, National Institute of the Chest and Hospital, Dhaka, Bangladesh, Mobile: 01711903377, E-mail: dr.mamun98@yahoo.com

Received: 12 March, 2013

Accepted: 17 November, 2014
He had prophylactic fluconazol and sulphamethoxazoltrimethoprime daily and pneumocaccal and influenza vaccination regularly and proper treatment of acute infective episodes accordingly. In spite all these measures, repeated infection caused grievous harm to his lung leading to irreversible pulmonary fibrosis and bronchiectasis. As a consequence, he became home bound, oxygen dependant and dependant on regular use of long acting bronchodilators in different form. Hematopoeitic stem cell transplantation was advised which was not affordable for his parents. Now, this young boy is waiting for further assaults to his lungs and further deterioration and ultimate hopeless outcomes.

Key words: Chronic granulomatous disease, Immunodeficiency disorder.

(J Banagladesh Coll Phys Surg 2015; 33: 156-160)

organisms ${ }^{3-8}$. Patients are particularly susceptible to fungal infection, typically from Aspergillus species, but also catalase positive bacteria including Staphylococcus aureus and Burkholderiacepacia. Most patients present with infections, typically lymph node abscesses, but also recurrent respiratory infection, deep-seated abscesses and septicaemia ${ }^{7,9-11}$. Since the 1960s, improved tests mean that CGD can be diagnosed easily and accurately ${ }^{12,13}$. More recently, the use of prophylactic antibiotics and anti-fungal agents appears to have reduced morbidity and mortality, but CGD remains a life-threatening condition ${ }^{14-16}$. However, little is known of the clinical course, complications and risk of death. Here, I report a case of chronic granulomatous disease with its clinical features, diagnostic works, management perspectives and adverse outcomes that will help our clinicians for early diagnosis and treatment of CGD in their clinical practice.

\section{Case Report:}

A 12 yrs' young boy, a student of class five was admitted to National Institute of Diseases of Chest and Hospital 
(NIDCH) on December 2012 with the complaints of severe breathlessness for 1 month and productive cough for same duration. On admission, his breathlessness was so severe that he couldn't speak in sentences and was sweaty. Sputum was muco-purulent, frothy and profuse. He had fever as well. On query, it was seen that he had been suffering from cough and breathlessness from his early childhood when he was only at three. Since then, he had repeated attack of cough and fever that was treated with different antibiotics by different internists and pulmonologists. He was treated with anti-TB drugs at least two times before, though there was no evidence of sputum microscopy and culture for acid-fast Bacilli (AFB) positive. Previous X-ray chest revealed nonhomogeneous opacities at different places of lungs with ring-like and reticular opacities throughout his lung fields. Interestingly, it was seen in serial chest x-rays that the opacities and shadows are changing in locations and textures. This patient hadn't suffered from chronic diarrhea, abdominal pain, serious skin infection or joint pain. He had parents and two sisters in his family and all were healthy.

On examination, the patient was dyspneic, cyanosed, and sweaty with puffy face and prominent accessory muscles of respiration. He was in sitting posture with a nasal canula on his face with oxygen cylinder beside his table. He was non-anemic, non-edematous, but had early clubbing. His respiratory rate was 34/min; Oxygen saturation was $88 \%$; temperature was $102^{0} \mathrm{~F}$, Pulse 112 / min, Blood pressure 110/75 mm of Hg. There was prominent scalene and supra-clavicular and suprasternal recession. Trechea was central, chest was expanded and breath sound was diminished vesicular with ronchi and crepitations in both lung fields.

Total white cell was $12,500 / \mathrm{cu} \mathrm{mm}$ and of them, neutrophils were $88 \%$. ESR was $76 \mathrm{~mm}$ in $1^{\text {st }} \mathrm{hr}$ and hemoglobin was $12 \mathrm{gm} / \mathrm{dl}$. Random blood sugar was $110 \mathrm{mg} / \mathrm{dl}$, serum creatinin $1.2 \mathrm{mg} / \mathrm{dl}$, billirubin $1.1 \mathrm{mg} / \mathrm{dl}$. Ultrasonography of abdomen was normal. Chest radiograph revealed opacity in right middle and lower zone with multiple rings like opacities in both lung fields. Computer tomographic scan of chest revealed ground glass opacities in right lower and part of its middle with bilateral reticular and reticulo-nodular opacities. Sputum culture was done at times. Different organisms was identifies, mostly pseudomonas auroginosa, Klibsiellaspp, Enterococcus, Coagulase negative Staphylococcus spp, Serratiaemarcescens etc. Sputum AFB microscopy And AFB culture was done this time and for three occasions previously and it was never seen positive. There was a fine needle aspiration cytology (FNAC) done previously in 2003 from an opacity in mid-lung of right side and that cytology revealed non-caseating chronic granulomatous lesions. At that time, he was sent abroad for further evaluation and a Nitroblu-tetrazolium test (NBT) was done which was found positive. Since then, he was taking sulphamethoxazole-trimethoprime $960 \mathrm{mg}$ and fluconazole $50 \mathrm{mg}$ daily as prophylaxis. In spite of all these efforts, he developed recurrent episodes of fever

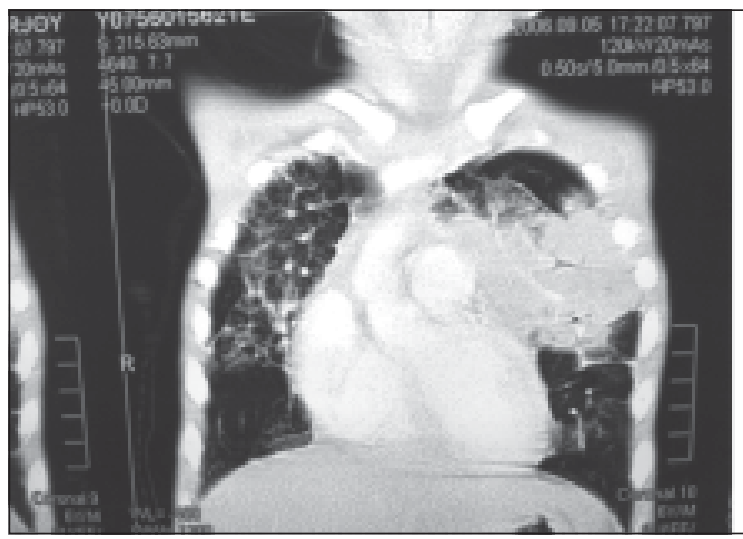

A.

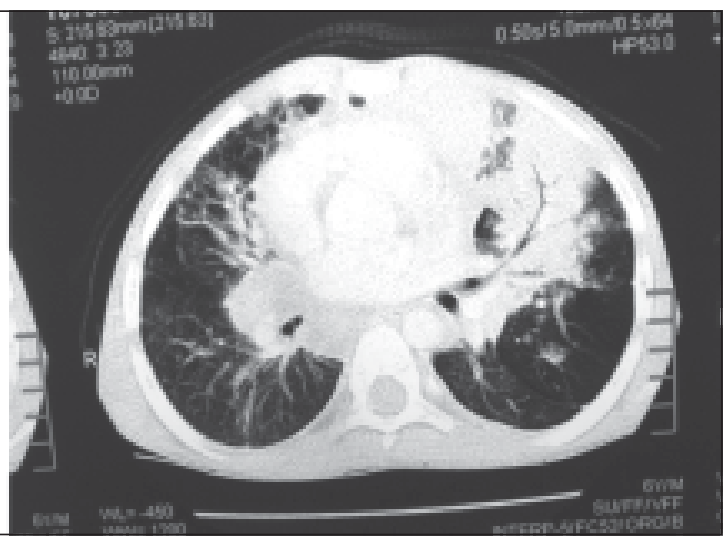

B.

Fig-1 A \& B: CT scan of Chest done in 2005 shows homogeneous opacities more marked in left side with bilateral reticular opacities 


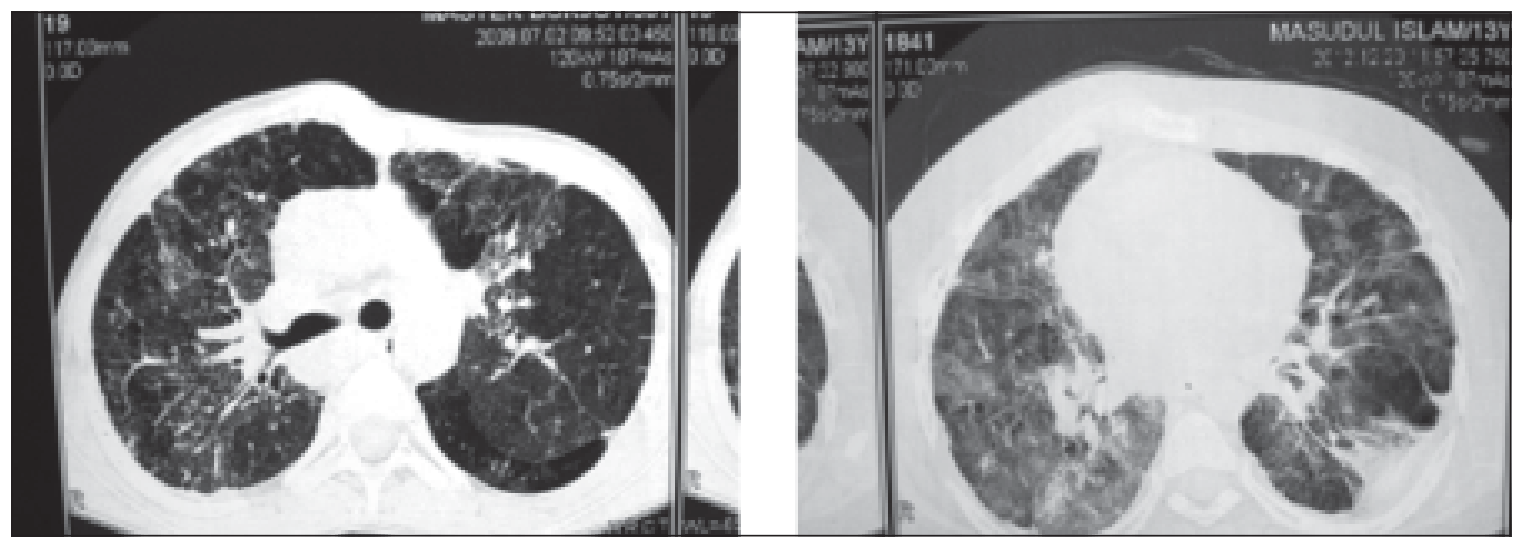

A.

Fig.-2 A \& B: Serial CT scan done in 2007 (A), 2012 (B) showed opacities in different places of lung with bilateral reticular lesions and cystic air spaces.

and productive cough with increasing breathlessness. He used to take different antibiotics in each episode. Now patient can't walk meters without breathlessness, defecate in a chair-bound toilet in bed room, had to take oxygen 3 liter/ min for at least 15 hrs at home and frequently in demand for salbutamol and ipratropium nebulization. Regularly he was taking salmeterol and fluticason inhaler twice daily, nebulized $\mathrm{N}$-acetyle cysteine twice daily, nutitionalsuppliments as required. Prophylactic sulphamethoxazole-trimethoprime 960mg and itraconazole $100 \mathrm{mg}$ daily was prescribed to prevent infection and warfarin 5mg daily to prevent thromboembolism was prescribed. He was taking yearly prophylactic pneumococcal vaccine and influenza vaccine.

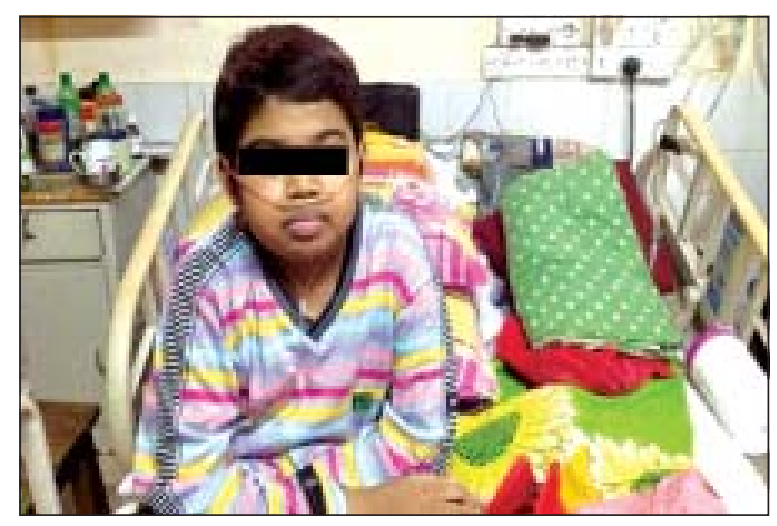

Fig-3: The photography of the unlucky young boy who is almost bound to his bed and dependant on oxygen and other respiratory appliances
This acute episode of pulmonary infection was treated with per-enteral hydrocortisone thrice daily, parenteral colistin thrice daily, perenteralvancomycin twice daily, nebulized tobramycin twice daily and nebulized Nacetylecystene thrice daily with high flow oxygen and bronchodialatornebulizations for 10 days. In spite of all these medications, patient had persistent low-grade fever at evening along with cough and breathlessness at the same time. So, lastly he was put on anti-TB treatment empirically for two weeks and observed improvement with the regime. Then patient was discharged with antiTB, prophylactic antibiotics and Bronchodialators.

\section{Discussion:}

Chronic granulomatous disease (CGD) (also known as Bridges-Good syndrome, and Quie syndrome ${ }^{1}$ ) is a diverse group of hereditary diseases in which certain cells of the immune system have difficulty forming the reactive oxygen compounds (most importantly, the superoxide radical) used to kill certain ingested pathogens. ${ }^{2}$ This leads to the formation of granulomata disease are transmitted as a mutation on the $\mathrm{X}$ chromosome and are thus called an "X-linked trait". ${ }^{17}$ The affected gene on the $\mathrm{X}$ chromosome codes for the gp91 proteinp91-PHOX. CGD can also be transmitted in an autosomal recessive fashion (via CYBA and NCF1) and affects other PHOX proteins. The type of mutation that causes both types of CGD is varied and may be deletions, frame-shift, nonsense, and missense. ${ }^{18,} 19$ in many organs. ${ }^{3}$ Most cases of chronic granulomatous 
Patients with the $\mathrm{X}$-linked recessive form of the disease appear to have a more serious clinical phenotype than patients with the autosomal recessive forms of the disease, based on the fact that they are diagnosed significantly earlier (mean, 3.01 years of age versus 7.81 years of age, respectively), have a significantly higher prevalence of perirectal abscess (17\% versus 7\%), suppurative adenitis (59\% versus 32\%), bacteremia/ fungemia (21\% versus 10\%), gastric obstruction (19\% versus 5\%), and urinary tract obstruction (11\% versus $3 \%$ ), and a higher mortality (21.2\% versus $8.6 \%$ ) 17 .Though no genetic analysis was done in our patient, it was likely to be of X-linked assumed from his family tree, he had no extra-pulmonary illness; but clinical course was aggressive like XL form.

The nitroblue-tetrazolium (NBT) test is the original and most widely-known test for chronic granulomatous disease. ${ }^{20}$ It is positive in CGD, meaning that it does not turn blue. The higher the blue score, the better the cell is at producing reactive oxygen species. This test depends upon the direct reduction of NBT by superoxide free radical to form an insoluble formazan. This test is simple to perform and gives rapid results, but only tells whether or not there is a problem with the PHOX enzymes, not how much they are affected. A similar test uses dihydrorhodamine (DHR) where whole blood is stained with DHR, incubated, and stimulated to produce superoxide radicals which reduce DHR to rhodamin in cells with normal function. An advanced test called the cytochrome $\mathrm{C}$ reduction assay tells physicians how much superoxide a patient's phagocytes can produce. Once the diagnosis of CGD is established, a genetic analysis may be used to determine exactly which mutation is the underlying cause.

Gene therapy is currently being studied as a possible treatment for chronic granulomatous disease. CGD is well-suited for gene therapy since it is caused by a mutation in single gene which only affects one body system (the hematopoietic system). Viruses have been used to deliver a normal gp91 gene to rats with a mutation in this gene, and subsequently the phagocytes in these rats were able to produce oxygen radicals. ${ }^{21}$

In 2006, two human patients with X-linked chronic granulomatous disease underwent gene therapy and blood cell precursor stem cell transplantation to their bone marrow. Both patients recovered from their CGD, clearing pre-existing infections and demonstrating increased oxidase activity in their neutrophils. However, long-term complications and efficacy of this therapy are unknown. ${ }^{22}$

Chronic granulomatous disease was first described as 'fatal granulomatous disease of childhood'1. Since then advances in the management and treatment of these patients have led to an improvement in life expectancy. However, many still have a chronic disease, which results in prolonged episodes of hospital admission and debilitation $^{23}$. As CGD is a multi-faceted disease with a wide spectrum of disease severity, it may present to a variety of specialists and it is vital to raise awareness of this condition so that appropriate treatment can be instituted promptly.

\section{References:}

1. Berendes H, Bridges RA, Good RA. A fatal granulomatosus of childhood.Minn Med. 1957; 40: 309-12

2. Landing BH, Shirkey HA. A syndrome of recurrent infection and infiltration of viscera by pigmented lipid histiocytes.Pediatrics. 1957;20:431-8

3. Segal AW, Peters TJ. Characterisation of the enzyme defect in chronic granulomatous disease.Lancet. 1976;1:1363-5

4. Curnutte JT, Whitten D, Babior BM. Defective superoxide production by granulocytes from patients with chronic granulomatous disease. N Engl J Med. 1974;290:593-7

5. Dinauer MC, Orkin SH, Brown R, Jesaitis AJ, Parkos CA. The glycoprotein encoded by the $\mathrm{X}$-linked chronic granulomatous disease locus is a component of the neutrophil cytochrome b complex. Nature. 1987;327: 717-20.

6. Smith RM, Curnutte JT. Molecular basis of chronic granulomatous disease. Blood. 1991;77:673-87.

7. Segal BH, Leto TL, Gallin JI, Malech HL, Holland SM. Genetic, biochemical and clinical features of chronic granulomatous disease. Medicine. 2000;79: 170-200.

8. Ahluwalia J, Tinker A, Clapp LH, et al. The largeconductance $\mathrm{Ca} 2+$-activated $\mathrm{K}+$ channel is essential for innate immunity. Nature. 2004;427:853-8.

9. Mouy R, Fischer A, Vilmer E, Seger R, Griscelli C. Incidence, severity, and prevention of infections in chronic granulomatous disease. J Pediatr. 1989;114:555-60.

10. Goldblatt D, Thrasher AJ. Chronic granulomatous disease.ClinExpImmunol. 2000; 122: 1-9

11. Hitzig WH, Seger R. Chronic granulomatous disease, a heterogeneous syndrome. Hum Genet. 1983;64:207-15. 
12. Baehner RL, Boxer LA, Davis J. The biochemical basis of nitrobluetetrazlium reduction in normal human and chronic granulomatous disease polymorphonuclear leukocytes. Blood. 1976;48: 309-13.

13. Vowells S, Sekhsaria S, Malech HL, Shalit M, Fleisher TA. Flow cytometric analysis of the granulocyte respiratory burst: a comparison study of fluorescent probes. J Immunol Methods. 1995; 178: 89-97

14. Finn A, Hadzic N, Morgan G, Strobel S, Levinsky RJ. Prognosis of chronic granulomatous disease. Arch Dis Child. 1990;65:942-5.

15. Liese JG, Jendrossek V, Jansson A, et al. Chronic granulomatous disease in adults. Lancet. 1996;347:220-3.

16. Cale CM, Jones AM, Goldblatt D. Follow up of patients with chronic granulomatous disease diagnosed since 1990. ClinExpImmunol 2000; 120: 351-5.

17. Winkelstein J, Marino M, Johnston R et al. Chronic granulomatous disease. Report on a national registry of 368 patients. Medicine 2000; 79: 155-69.

18. Heyworth P, Curnutte J, Rae J, Noack D et al. "Hematologically important mutations: X-linked chronic granulomatous disease”. Blood Cells Mol Dis 2001; 27: $16-26$

19. Cross A, Noack D, Rae J, Curnutte J, Heyworth P Hematologically important mutations: the autosomal recessive forms of chronic granulomatous disease. Blood Cells Mol Dis 2000; 26: 561-5.

20. Kasper DL, Fauci AS, Longo DL, Braunwald E, Hauser SL, and Jameson JL. In: Harrison's Principles of Internal Medicine, 16th edition 2005; 357

21. Dinauer M, Gifford M, Pech N et al. Variable correction of host defense following gene transfer and bone marrow transplantation in murine $\mathrm{X}$-linked chronic granulomatous disease. Blood 2001; 97: 3738-45

22. Ott M, Schmidt M, Schwarzwaelder K et al. Correction of $\mathrm{X}$-linked chronic granulomatous disease by gene therapy, augmented by insertional activation of MDS1-EVI1, PRDM16 or SETBP1. Nat Med 2006; 12: 401-9

23. Liese J, Kloos S, Jendrossek V, et al. Long-term follow-up and outcome of 39 patients with chronic granulomatous disease. J Pediatr.2000; 137: 687-93 